\title{
PERFIL EPIDEMIOLÓGICO DOS ACIDENTES COM EXPOSIÇÃO À MATERIAIS BIOLÓGICOS OCORRIDOS EM TRABALHADORES NO ESTADO DO AMAPÁ, AMAZÔNIA, BRASIL, DE 2015 A 2019
}

\section{ARTIGO ORIGINAL}

MACIEL, Danilo Pereira Garcia ${ }^{1}$, MEDEIROS, José Leandro Tomaz², SILVA, Mariana Freitas $\mathrm{da}^{3}$, SILVA, Matheus Freitas da ${ }^{4}$, FECURY, Amanda Alves ${ }^{5}$, DIAS, Claudio Alberto Gellis de Mattos $^{6}$, OLIVEIRA, Euzébio de ${ }^{7}$, DENDASCK, Carla Viana $^{8}$, DAHER, Donizete Vago ${ }^{9}$, ARAÚJO, Maria Helena Mendonça de ${ }^{10}$

MACIEL, Danilo Pereira Garcia. Et al. Perfil epidemiológico dos acidentes com exposição à materiais biológicos ocorridos em trabalhadores no Estado do Amapá, Amazônia, Brasil, de 2015 a 2019. Revista Científica Multidisciplinar Núcleo do Conhecimento. Ano 06, Ed. 03, Vol. 04, pp. 127-141. Março de 2021. ISSN: 2448-0959, Link de acesso:

https://www.nucleodoconhecimento.com.br/saude/exposicao-a-materiais, DOI: 10.32749/nucleodoconhecimento.com.br/saude/exposicao-a-materiais

\footnotetext{
${ }^{1}$ Estudante de Graduação no Curso de Medicina da Universidade Federal do Amapá (UNIFAP).

${ }^{2}$ Estudante de Graduação no Curso de Medicina da Universidade Federal do Amapá (UNIFAP).

${ }^{3}$ Estudante de Graduação no Curso de Medicina da Universidade Federal do Amapá (UNIFAP).

${ }^{4}$ Estudante de Graduação no Curso de Medicina da Universidade Estadual do Pará (UEPA).

${ }^{5}$ Biomédica, Doutora em Doenças Topicais, Professora e pesquisadora do Curso de Medicina do Campus Macapá, Universidade Federal do Amapá (UNIFAP).

${ }^{6}$ Biólogo, Doutor em Teoria e Pesquisa do Comportamento, Professor e pesquisador do Curso de Licenciatura em Química do Instituto de Ensino Básico, Técnico e Tecnológico do Amapá (IFAP) e do Programa de Pós Graduação em Educação Profissional e Tecnológica (PROFEPT IFAP).

${ }^{7}$ Biólogo, Doutor em Doenças Topicais, Professor e pesquisador do Curso de Educação Física da, Universidade Federal do Pará (UFPA).

${ }^{8}$ Teóloga, Doutora em Psicanálise, pesquisadora do Centro de Pesquisa e Estudos Avançados - CEPA.

${ }^{9}$ Enfermeira e Obstetra, Doutora em Saúde Coletiva (FCM-UNICAMP), Professora e pesquisadora na Universidade Federal Fluminense (UFF).

${ }^{10}$ Médica, Mestra em Ensino e Ciências da Saúde. Professora e pesquisadora na Universidade Federal do Amapá (UNIFAP), campus Macapá, AP.
}

RC: 77957

Disponível em: https://www.nucleodoconhecimento.com.br/saude/exposicao-a- 


\section{RESUMO}

Exposições acidentais com instrumentos perfurocortantes são os acidentes de trabalho mais comuns envolvendo profissionais e estudantes em ambiente hospitalar. Acidente com material biológico (MB) decorre do contato direto entre sangue e fluidos orgânicos genitais ou de serosas, com pele não íntegra, mucosas ou por inoculação percutânea direta através de objetos perfurocortantes. O objetivo deste trabalho foi caracterizar o perfil epidemiológico dos acidentes com exposição à materiais biológicos ocorridos em trabalhadores no estado do Amapá, Amazônia, Brasil, no período de 2015 a 2019, analisando o número, tipo de ocorrências, ocupação e circunstância do acidente. Realizou-se um estudo epidemiológico retrospectivo descritivo, transversal, com abordagem quantitativa. Assim, foram pesquisadas na base de dados do Sistema de Informação de Agravos de Notificação (SINAN) registros referentes às notificações de acidentes com material biológico, ocorridos no estado do Amapá no período de 2015 a 2019, registrados pelo Núcleo de Vigilância em Saúde do Trabalhador (NVST)/Centro de Referência da Saúde do Trabalhador (CEREST/AP). As exposições ocupacionais à materiais biológicos representam um potencial risco de transmissão de doenças. Instruir os trabalhadores a comunicarem imediatamente os acidentes ocorridos é essencial para abastecer o sistema de notificações. Em relação às circunstâncias, as duas causas mais comumente encontradas foram com valores próximos entre si, a administração de medicações (21,6\%) e descarte inadequado do material (20\%). Esse descarte incorreto, demonstra a falta de zelo dos profissionais sobre sua própria saúde.

Palavras-chave: Acidentes Biológicos, exposição, epidemiologia, Amazônia, trabalhador.

$\mathrm{RC}: 77957$

Disponível em: https://www.nucleodoconhecimento.com.br/saude/exposicao-a- 


\section{INTRODUÇÃO}

Exposições acidentais com instrumentos perfurocortantes são os acidentes de trabalho mais comuns envolvendo profissionais e estudantes em ambiente hospitalar. Estima-se que anualmente, ocorram aproximadamente 385.000 casos de acidentes com perfurocortantes envolvendo profissionais de saúde que atuam em hospitais de todo o mundo, de acordo com o Centers for Diseases Control and Prevention - CDC (RUAS et al., 2012; CUNHA te al., 2019).

Acidente com material biológico (MB) decorre do contato direto entre sangue e fluidos orgânicos genitais ou de serosas, com pele não íntegra, mucosas ou por inoculação percutânea direta através de objetos perfurocortantes. Exposição ocupacional ocorre durante o exercício do trabalho, seja em serviços destinado à prestação de assistência à saúde da população, seja durante a coleta de resíduos ou qualquer outra função de trabalho desempenhada e compõe a Lista Nacional de Doenças de Notificação Compulsória (BRASIL, 1991; DAROUICHE et al., 2014; ARAÚJO et al., 2019).

Dentre os mais de vinte patógenos envolvidos nas exposições acidentais, destacamse o Vírus da Hepatite B (HBV), Vírus da Hepatite C (HCV) e o Vírus da Imunodeficiência Humana (HIV), pelo risco de transmissão que é estimado entre 6\% e $30 \%$ para o HBV; entre $5 \%$ e $10 \%$ para HCV e 0,3\% para HIV, após uma lesão com objeto perfurante (CDC,2001). Além dos patógenos virais, o agente etiológico Clostridium tetani, causa o tétano acidental, através da inoculação dos esporos em mucosas e pele não íntegra, especialmente em ferimentos superficiais profundos envolvendo de materiais com descarte incorreto (BRASIL, 2018; SILVA et al., 2020). O risco de se adquirir uma infecção por meio dessas exposições depende de fatores como: extensão da lesão, volume de fluído biológico presente, condições sistêmicas do acidentado, características dos microrganismos presentes, estado sorológico da

RC: 77957

Disponível em: https://www.nucleodoconhecimento.com.br/saude/exposicao-amateriais 
pessoa-fonte, bem como as condutas realizadas após a exposição (BRASIL, 2017, VASCONCELOS et al., 2020).

A Portaria ํํ 1061/2020 estabelece que os Acidentes de Trabalho com Exposição a Material Biológico, é de notificação compulsória e devem de inseridos no Sistema de Informação de Agravos de Notificação (SINAN) semanalmente. No momento do atendimento do acidente, é necessário o preenchimento da ficha de notificação individual (FNI), porém, não se deve aguardar o preenchimento da FNI para prestar atendimento ao trabalhador (BRASIL, 2020).

A principal forma de se evitar a exposição é a educação preventiva e o uso adequado de Equipamento de Proteção Individual (EPI), observando-se assim as normas de biossegurança. É importante avaliar o status sorológico tanto da pessoa exposta quanto do pessoa-fonte. A Profilaxia Pós Exposição (PEP), deve ser iniciada nas primeiras horas do acidente, sendo indicado como PEP para o HIV a Terapia Antirretroviral (TARV), e recomendação de complementação vacinal ou imunização passiva para Hepatites Virais e Tétano (BRASIL, 2017).

\section{OBJETIVO}

Caracterizar o perfil epidemiológico dos acidentes com exposição à materiais biológicos ocorridos em trabalhadores no estado do Amapá, Amazônia, Brasil, no período de 2015 a 2019, analisando o número, tipo de ocorrências, ocupação e circunstância do acidente.

\section{MÉTODO}

Realizou-se um estudo epidemiológico retrospectivo descritivo, transversal, com abordagem quantitativa. Assim, foram pesquisadas na base de dados do Sistema de Informação de Agravos de Notificação (SINAN) registros referentes às notificações de acidentes com material biológico, ocorridos no estado do Amapá no período de

RC: 77957

Disponível em: https://www.nucleodoconhecimento.com.br/saude/exposicao-amateriais 
2015 a 2019, registrados pelo Núcleo de Vigilância em Saúde do Trabalhador (NVST)/Centro de Referência da Saúde do Trabalhador (CEREST/AP).

Nesse sentido, as variáveis analisadas incluíram a quantidade total de acidente, o número de casos separados por ano, a ocasião na qual ocorreu o acidente, o sexo biológico e a ocupação dos acidentados.

Os números foram obtidos no mês de outubro de 2020 por meio da exportação de registros do SINAN pelo programa Tabwin, desenvolvido pelo DATASUS/Ministério da Saúde, para planilhas do programa Microsoft Excel. Sendo então compilados, tabulados e analisados, foram calculados e expressos em frequências absolutas e relativas e, por fim, analisados em conjunto com a pesquisa literária levantada. Devido ao domínio público-administrativo dos dados secundários, não foi necessário o parecer do Comitê de Ética em Pesquisa, de acordo com a Resolução 466-2012.

\section{RESULTADOS}

Durante o quinquênio de 2015-2019, registrou-se 860 casos de acidentes com material biológico notificados no SINAN. O ano em que mais acidentes ocorreram foi 2016 (199 casos $=23,1 \%$ ), contrastando com o ano anterior, em que houve o menor índice de registros, 2015 (128 casos = 14,8\%) (Figura 1).

RC: 77957

Disponível em: https://www.nucleodoconhecimento.com.br/saude/exposicao-a- 
Figura 1 Mostra 0 número de acidentes de trabalho com exposição a material biológico no estado do Amapá, Amazônia, Brasil entre 2015 e 2019.

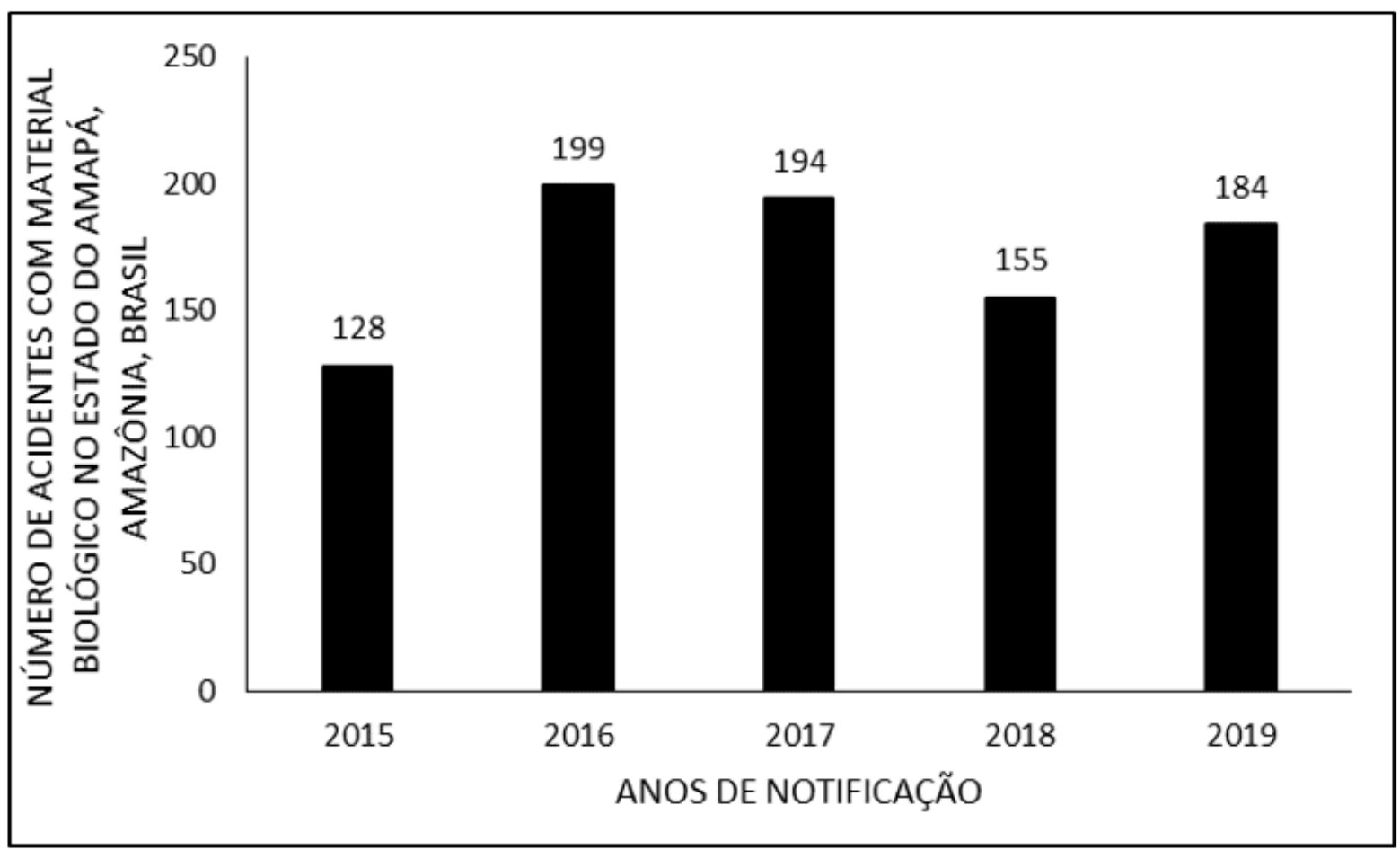

Fonte: SINAN, 2020.

O sexo feminino com 595 casos $(69,1 \%)$ foi predominante sobre o masculino, que ocupou menos de um terço dos casos registrados, 265 (30,8\%) (Figura2).

RC: 77957

Disponível em: https://www.nucleodoconhecimento.com.br/saude/exposicao-a- 
Figura 2 Mostra o número de acidentes de trabalho com exposição a material biológico no estado do Amapá, Amazônia, Brasil entre 2015 e 2019, por gênero (sexo).

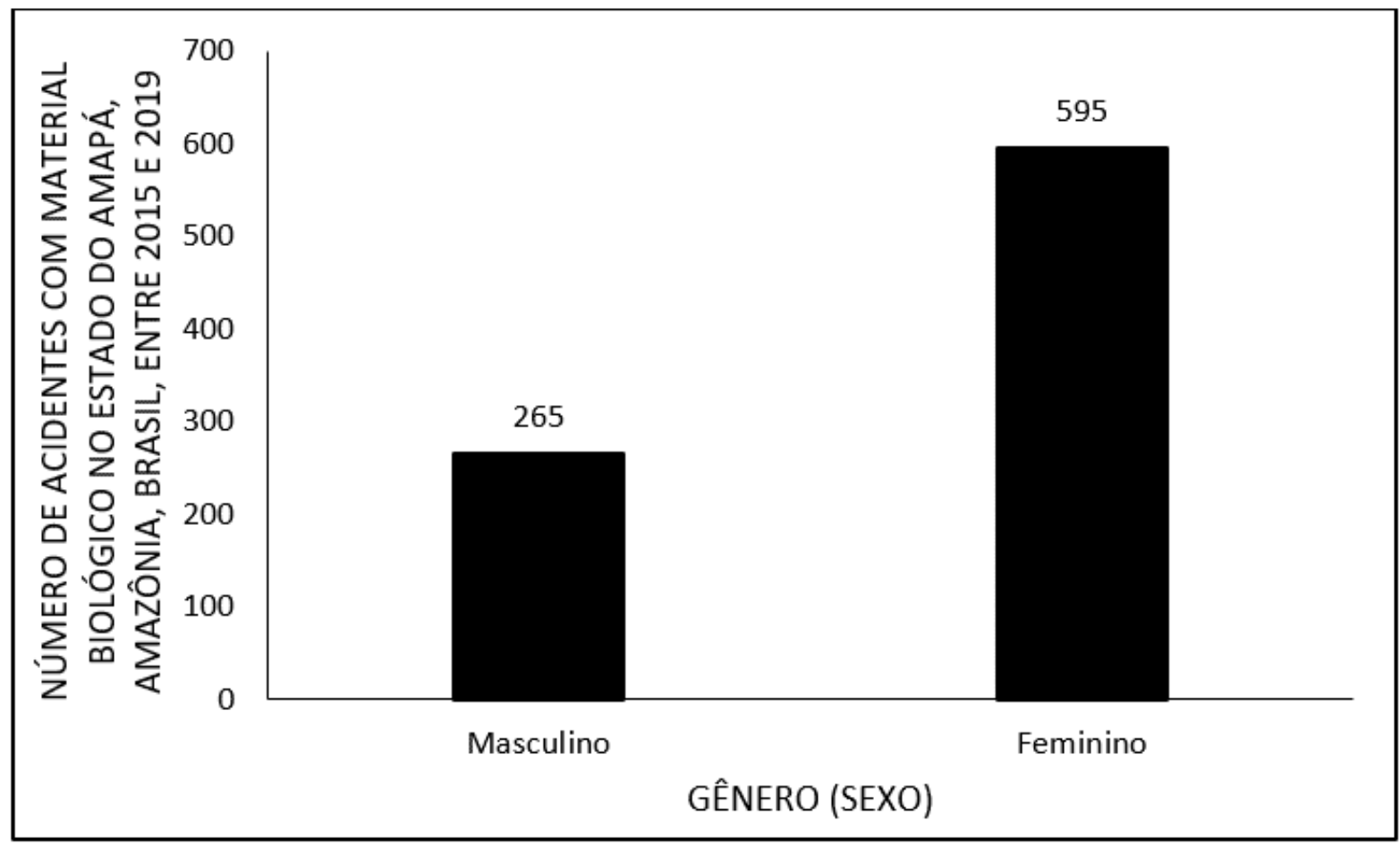

Fonte: SINAN, 2020.

Quanto à ocupação profissional, a classe mais envolvida nos acidentes foi a dos profissionais de enfermagem (346 casos $=40,13 \%$ ), assim distribuídos: 300 técnicos de enfermagem (34,9\%), 45 enfermeiros (5,23\%). A segunda colocação é ocupada pelos estudantes, com 116 casos (13,4\%). Seguida dos servidores de saneamento (faxineiros, coletores de lixo e garis), com quantitativo de 66 casos (7,8\%). A classe médica possui um montante de 35 casos (4,06\%), quando somadas todas as especialidades, sendo as maiores incidências entre os médicos clínicos (1,86\%), e cirurgiões gerais (1,04\%). Os profissionais dentistas representam 24 casos $(2,7 \%)$, porém, os técnicos de higiene dental, apresentam um valor superior de acidentes 53 casos $(6,16 \%)$, quando comparado aos dentistas. Farmacêuticos, fisioterapeutas e biomédicos somados, representam $1,62 \%$ do total de casos (Tabela 1).

$\mathrm{RC}: 77957$

Disponível em: https://www.nucleodoconhecimento.com.br/saude/exposicao-a- 
Tabela 1 Mostra o número de acidentes de trabalho com exposição a material biológico no estado do Amapá, Amazônia, Brasil entre 2015 e 2019, quanto a ocupação.

\begin{tabular}{c|c|c|c|c|c|c}
\cline { 2 - 7 } & $\mathbf{2 0 1 5}$ & $\mathbf{2 0 1 6}$ & $\mathbf{2 0 1 7}$ & $\mathbf{2 0 1 8}$ & $\mathbf{2 0 1 9}$ & TOTAL \\
\hline $\begin{array}{c}\text { Profissionais de } \\
\text { enfermagem }\end{array}$ & 73 & 70 & 76 & 65 & 62 & 346 \\
\hline $\begin{array}{c}\text { Estudantes } \\
\text { Gari, faxineiro, coletor de } \\
\text { lixo }\end{array}$ & 10 & 27 & 32 & 22 & 25 & 116 \\
\hline $\begin{array}{c}\text { Profissionais médicos } \\
\text { Cirurgião dentista }\end{array}$ & 3 & 13 & 8 & 4 & 7 & 35 \\
\hline $\begin{array}{c}\text { Outros profissionais de } \\
\text { saúde }\end{array}$ & 4 & 10 & 6 & 9 & 24 & 53 \\
\hline $\begin{array}{c}\text { Profissionais de outras } \\
\text { áreas }\end{array}$ & 14 & 71 & 52 & 29 & 32 & 198 \\
\hline TOTAL & $\mathbf{9 1}$ & $\mathbf{1 2 1}$ & $\mathbf{1 2 3}$ & $\mathbf{1 1 1}$ & $\mathbf{1 2 8}$ & $\mathbf{8 3 8}$ \\
\hline
\end{tabular}

Fonte: SINAN, 2020.

Considerando a variável circunstância do acidente, a causa mais comum de agravos envolvendo materiais biológicos foi a administração de medicações $(21,6 \%)$, seguida de descarte inadequado de material (20\%), e procedimentos cirúrgico-odontológicos (15\%). Outras duas causas com destaque foram a manipulação da caixa de descarte de perfurocortantes (3,9\%) e reencape de agulha (2,32\%) (Tabela 2$)$.

RC: 77957

Disponível em: https://www.nucleodoconhecimento.com.br/saude/exposicao-a- 
Tabela 2 Mostra o número de acidentes de trabalho com exposição a material biológico no estado do Amapá, Amazônia, Brasil entre 2015 e 2019, quanto a ocasião.

\begin{tabular}{|c|c|c|c|c|c|c|}
\hline & 2015 & 2016 & 2017 & 2018 & 2019 & Total \\
\hline $\begin{array}{c}\text { Administração } \\
\text { endovenosa }\end{array}$ & 22 & 23 & 21 & 15 & 22 & 103 \\
\hline $\begin{array}{l}\text { Descarte inadequado } \\
\text { lixo }\end{array}$ & 20 & 17 & 21 & 18 & 18 & 94 \\
\hline $\begin{array}{c}\text { Descarte inadequado } \\
\text { chão }\end{array}$ & 13 & 16 & 26 & 9 & 14 & 78 \\
\hline $\begin{array}{l}\text { Procedimento } \\
\text { odontológico }\end{array}$ & 2 & 20 & 13 & 17 & 23 & 75 \\
\hline $\begin{array}{l}\text { Administração } \\
\text { intramuscular }\end{array}$ & 5 & 8 & 12 & 21 & 15 & 61 \\
\hline Procedimento cirúrgico & 4 & 21 & 12 & 4 & 13 & 54 \\
\hline Punção coleta & 9 & 7 & 5 & 6 & 9 & 36 \\
\hline $\begin{array}{c}\text { Manipulação de caixa } \\
\text { perfuro/cortante }\end{array}$ & 4 & 6 & 9 & 9 & 6 & 34 \\
\hline Lavagem de material & 6 & 4 & 8 & 3 & 10 & 31 \\
\hline $\begin{array}{c}\text { Procedimento } \\
\text { laboratorial }\end{array}$ & 2 & 2 & 4 & 5 & 10 & 23 \\
\hline Punção NE & 6 & 5 & 4 & 3 & 2 & 20 \\
\hline Lavanderia & 2 & 15 & 0 & 2 & 1 & 20 \\
\hline Reencape & 2 & 6 & 2 & 5 & 5 & 20 \\
\hline $\begin{array}{c}\text { Administração } \\
\text { subcutânea }\end{array}$ & 0 & 7 & 6 & 0 & 1 & 14 \\
\hline Dextro & 7 & 0 & 4 & 0 & 1 & 12 \\
\hline $\begin{array}{c}\text { Administração } \\
\text { intradérmica }\end{array}$ & 3 & 3 & 2 & 0 & 0 & 8 \\
\hline Ignorado/Branco & 4 & 10 & 11 & 11 & 2 & 38 \\
\hline Outros & 17 & 29 & 34 & 27 & 32 & 139 \\
\hline Total & 128 & 199 & 194 & 155 & 184 & 860 \\
\hline
\end{tabular}

Fonte: SINAN, 2020.

RC: 77957

Disponível em: https://www.nucleodoconhecimento.com.br/saude/exposicao-a- 


\section{DISCUSSÃO}

Com base nos dados apresentados, é possível constatar que as mulheres são a principal força de trabalho envolvidas nos acidentes com material biológico $(69,1 \%)$. Uma análise de série histórica lançada em formato de boletim epidemiológico realizada no Rio de Janeiro entre os anos 2009-2020, revelou uma proporção aproximada de um homem para cada três mulheres que sofrem acidente (Brasil, 2020; CARNEIRO et al., 2020). Resultado semelhante foi encontrado no estudo de Khalil et al., (2015) realizado em um serviço de atenção especializada no sudeste do Brasil, onde mulheres sofreram três vezes mais acidentes comparadas aos homens.

Dentre as ocupações analisadas, notou-se a categoria dos profissionais da saúde $(60,11 \%)$, como sendo os principais acidentados, isso decorre do fato desses profissionais estarem em contato direto com pacientes, realizando procedimentos e manipulando materiais potencialmente contaminados (MOREIRA et al., 2020). Esses achados foram equivalentes a estudos realizados em outros países como Egito e Itália (TALAAT et al., 2003; MAIDA et at., 2020).

De acordo com os resultados da pesquisa em tela, os profissionais de enfermagem foram a categoria mais envolvida em acidentes, seguidos de estudantes, corroborando com o achado de Santos (2015) que em sua pesquisa demonstrou que os técnicos de enfermagem seguidos de acadêmicos de medicina foram os mais acometidos por acidentes com perfurocortantes. Nesse sentido, também há o estudo de Kon et al (2011) em um Hospital de Curitiba (PR) em que a maior parte dos acidentes acometeram os auxiliares de enfermagem $(30,1 \%)$, técnico de enfermagem $(15 \%, 2)$ e estudantes $(10,8 \%)$ notificados e registrados no SINAN.

Figueiredo (2018), analisando os profissionais envolvidos nos acidentes com materiais biológicos, observou que, dentre os casos analisados, $47 \%$ trabalhavam na área de enfermagem; 19\% foram estudantes, 6\% foram médicos; $6 \%$ cirurgiões dentista, $4 \%$ foram trabalhadores nos serviços de coleta, de resíduos, de limpeza e

$\mathrm{RC}: 77957$

Disponível em: https://www.nucleodoconhecimento.com.br/saude/exposicao-a- 
conservação de áreas públicas. Corroborando esses dados, em primeiro lugar aparecem os técnicos de enfermagem, com mais de um terço dos casos de acidentes publicados. Esses profissionais, constituem os trabalhadores de maior número nos serviços, realizando diretamente a assistência aos pacientes (NEIVA et al., 2019). Oliveira et al. (2015), publicou um trabalho epidemiológico de acidentes com MB entre profissionais da enfermagem de uma cidade do Ceará, do montante de 277 notificações de acidentes, 217 eram auxiliares de enfermagem (78,3\%), confirmando serem esses profissionais os mais expostos à acidentes.

Os estudantes configuram a segunda categoria predominante nos acidentes com material biológico, correspondendo a $13,4 \%$ do total analisado. Isso pode ser decorrente do fato de estarem em período de treinamento e formação, portanto apresentando inexperiência profissional durante a realização técnica de procedimentos e manipulação materiais. Reis et al. (2013) conduziram um estudo epidemiológico dos acidentes com material biológico em um pronto socorro cirúrgico envolvendo estudantes de medicina, e identificaram que dentre os 100 alunos participantes, um percentual de 32\% sofreu esse tipo de acidente no ano de 2012. Os principais fatores identificados nesse estudo foram falta de treinamento e não uso de equipamentos de proteção individual.

É importante destacar também os profissionais que trabalham na limpeza, pois representam o terceiro grupo de maior risco de contaminação com material biológico, por terem contato direto com resíduos orgânicos e hospitalares (MATOS et al., 2019). Eles são representados pelos coletores de lixo, faxineiros e garis. Canini; Gir e Machado (2005) desenvolveram um estudo onde trabalhadores do serviço de apoio que sofreram acidentes com potencial risco de contaminação, foram acompanhados em um hospital universitário terciário de São Paulo pelo período de aproximadamente quatro anos. Verificou-se que a maioria $(94,9 \%)$ dos acidentes não foi possível descobrir a pessoa-fonte, necessitando de PEP com uso de TARV e se deu por descarte incorreto de agulhas.

RC: 77957

Disponível em: https://www.nucleodoconhecimento.com.br/saude/exposicao-amateriais 
Verifica-se com o resultado desses dados, a diferença no número de acidentes comparando diferentes categorias de profissionais da saúde. Médicos (4,06\%) tiverem uma incidência superior aos dentistas $(2,7 \%)$ no estado do Amapá. Correspondentemente, constatou-se no estudo de Reis, Gómez, Diniz (2019), que médicos tiveram incidência mais elevada que os dentistas, explicada pela melhor adesão a medidas de precaução padrão. O mesmo padrão repetiu-se entre os estudantes de medicina versus odontologia - melhor adesão de precaução padrão.

Segundo Brozoski (2010) o acidente com material biológico ocorre durante a práticas em disciplinas de cirurgia no curso de odontologia com material de agulha de anestesia que são hipodérmicas e gengivais. Os dados mostram que o cirurgião dentista fica em quinto lugar com 24 casos durante o período, e a administração de medicamentos por via intradérmica tem apenas 8 casos notificados, o que gera margem para se considerar uma hipótese de subnotificação, que pode acontecer em mais de 95\% dos casos segundo Santos (2015).

Quando confrontado a diferença de casos de acidentes com MB entre médicos de especialidades clínicas e cirúrgicas, no Amapá, há um predomínio do primeiro sobre o segundo. Diferentemente do notado em um hospital universitário da Colômbia, em que os médicos residentes de áreas cirúrgicas tiveram 3,3 vezes mais acidentes que os médicos

residentes de áreas clínicas. (TAPIAS, TAPIAS, TORRES, 2007). Possivelmente essa diferença ocorra devido à falta de uniformidade de prevenção entre os locais e trabalho, mesmo havendo regras únicas (MATOS et al., 2019).

Em relação às circunstâncias, as duas causas mais comumente encontradas foram com valores próximos entre si, a administração de medicações $(21,6 \%)$ e descarte inadequado do material $(20 \%)$. Esse descarte incorreto, demonstra a falta de zelo dos profissionais sobre sua própria saúde. Cordeiro et al. (2016), encontrou resultados bastante próximos também envolvendo administração de medicamentos

RC: 77957

Disponível em: https://www.nucleodoconhecimento.com.br/saude/exposicao-amateriais 
$(9,7 \%)$ e descarte inadequado de materiais $(9,5 \%)$ em sua pesquisa realizada no estado da Bahia em 2012, com dados de 1613 casos do SINAN. Em contraste, Janjua, Khan, Mahmood (2010), observaram em seu estudo que o reencape de agulha foi a causa mais comum de acidente, por ter aumentado em duas vezes o risco de exposição percutânea.

\section{CONCLUSÕES}

As exposições ocupacionais à materiais biológicos representam um potencial risco de transmissão de doenças. Ainda existem alguns desafios a serem superados em relação à notificação e ações preventivas em acidentes laborais envolvendo os trabalhadores no Amapá.

Instruir os trabalhadores a comunicarem imediatamente os acidentes ocorridos é essencial para abastecer o sistema de notificações. Os dados corretamente preenchidos na ficha de notificação são importantes para ajudar monitorar a ocorrência de acidentes, garantir um seguimento precoce para mitigar a chance de contrair infecções, identificar atividades de maior risco, afim de reforçar a vigilância e melhorar as práticas de biossegurança e reduzir os riscos ocupacionais.

As principais formas de prevenção dos acidentes de trabalho são observar e seguir as medidas de segurança como o uso adequado de EPIs, cautela durante a administração de medicações, descarte correto dos materiais, esquema completo e atualizado de vacinação para hepatite $B$ e tétano e profilaxia pós-exposição com acompanhamento adequado. A prevenção dessas infecções constitui um pilar importante na segurança do trabalhador.

\section{REFERÊNCIAS}

ARAÚJO, A. F. B. et al. Internações por acidentes de trânsito no Estado do Amapá entre os anos 2014-2018 Revista Científica Multidisciplinar Núcleo do

RC: 77957

Disponível em: https://www.nucleodoconhecimento.com.br/saude/exposicao-a- 
Conhecimento, v. $1, \quad$ p. 1-10, 2019. Disponível em:< https://www.nucleodoconhecimento.com.br/saude/internacoes-por-acidentes >.

BRASIL. Portaria no 1061, de 18 de maio de 2020. Revoga A Portaria № 264, de 17 de Fevereiro de 2020, e Altera A Portaria de Consolidação № 4/gm/ms, de 28 de Setembro de 2017, Para Incluir A Doença de Chagas Crônica, na Lista Nacional de Notificação Compulsória de Doenças, Agravos e Eventos de Saúde Pública nos Serviços de Saúde Públicos e Privados em Todo O Território Nacional. 102. ed. Brasília, DF: Ministério da Saúde, 29 maio de 2020. Seção 1, p. 229.

BRASIL. Constituição (1990). Lei no 8213/91, de 24 de julho de 1991. Brasília, DF. 1991. Disponível em: http://www.planalto.gov.br/ccivil_03/leis//8213cons.htm. Acesso em: 18 fev. 2020.

BRASIL. Ministério da Saúde. Protocolo Clínico e Diretrizes Terapêuticas para Hepatite B e Coinfecções. Brasília: Secretaria de Vigilância em Saúde, Departamento de DST, Aids e Hepatites Virais, Ministério da Saúde, 2017.

BRASIL. Ministério da Saúde. Guia de Vigilância em Saúde: volume único. 2a edição. Brasília: Secretaria de Vigilância em Saúde, Coordenação-Geral de Desenvolvimento da Epidemiologia em Serviços. Ministério da Saúde, 2017.

BRASIL. Ministério da Saúde. Protocolo clínico e diretrizes terapêuticas para profilaxia pós-exposição (PEP) de risco à infecção pelo HIV, IST e hepatites virais. Brasília: Ministério da Saúde, 2017, p 164-172, volume único. Disponível em: Volume-Unico-2017.pdf (saude.gov.br) . Acesso em :10/02/2020.

BRASIL. Ministério da Saúde. Boletim Epidemiológico: Situação epidemiológica do tétano acidental no Brasil, 2007-2016. Volume 49/ Jun. 2018. Brasília: Secretaria de Vigilância em Saúde, 2018.

RC: 77957

Disponível em: https://www.nucleodoconhecimento.com.br/saude/exposicao-a- 
BROZOSKI, M.A.; Traina A.A.; NACLÉRIO-HOMEM, M.G.; DEBONI, M.C.Z. Ocorrência de acidentes perfurocortantes em um curso de odontologia. Rev Gaúcha Odontol, Porto Alegre: vol.58 n.1, p 77-80, 2010.

CANINI S.R.M.S.; GIR, E.; MACHADO, A. A. Accidents with potentially hazardousbiological material among workers in hospital supporting services. Revista Latino-Americana de Enfermagem, Ribeirão Preto, v. 13, n. 4, p. 496-500, jul/ago, 2005.

CARNEIRO, L. Q. C. et al. Perfil epidemiológico dos pacientes atendidos devido a acidentes ofídicos no norte do Brasil, Região Amazônica, no período de 2009 a 2019. Revista Científica Multidisciplinar Núcleo do Conhecimento, v. 3, p. 1-19, 2020. Disponível em: < https://www.nucleodoconhecimento.com.br/saude/acidentesofidicos $>$.

CDC. Guidelines for the management of occupational exposures to HBV, HCV, and HIV and recommendations for postexposure prophylaxis. Atlanta: MMWR Recomm Rep, v50(RR11),P 1-52, 2001.

CORDEIRO, T. M. S. C.; NETO, J. N. C.; CARDOSO, M. C. B. C.; MATTOS, A. I. S.; SANTOS, K. O. B.; ARAÚJO, T. M. Acidentes de trabalho com exposição à material biológico: Descrição dos casos na Bahia. Rev. Epidemiol. Control. Infec, Santa Cruz do Sul, v. 6, n. 2, p. 50-56, 2016.

CUNHA, A. A. et al. Tendência na incidência de acidentes de trajeto em trabalhadores no Brasil entre 2009 e 2016. Bras Med Trab., v. 17, n. 4, p. 490-498, 2019. Disponível em: < http://rbmt.org.br/about-the-authors/489/pt-BR >.

DAROUICHE, M.H., et al. Occupational blood exposure among health care personnel and hospital trainees. Int J Occup Environ Med. [S.I], v.5, n 1, p 57-61, 2014.

RC: 77957

Disponível em: https://www.nucleodoconhecimento.com.br/saude/exposicao-a- 
FIGUEIREDO, W. M.; et al. Acidentes ocupacionais por material de risco biológico: estudo etnográfico. Braz. J. of Develop, Curitiba, v. 4, n. 7, Edição Especial, p. 4500-4518, nov. 2018.

JANJUA, N.Z.; KHAN, M.I.; MAHMOOD, B. Sharp injuries and their determinants among health care workers at first-level care facilities in Sindh Province, Pakistan. Trop Med Int Health, [S.I] v15, p 1244-1251, 2010.

KHALIL, S.S.; KHALIL, O.A.K.; LOPES-JÚNIOR, L.C.; CABRAL, D.B.; BOMFIM, E.O.; LANDUCCI, L.F.; SANTOS, M.L.S.G. Occupational exposure to bloodborne pathogens in a specialized care service in Brazil. American Journal of Infection Control, [S.I], v43, n8, p. e39-e41, 2015.

KON, N.M.; SOLTOSKI, F.; REQUE JÚNIOR. M.; LOZOVEY, J.C.A. Acidentes de trabalho com material biológico em uma Unidade Sentinela: casuística de 2.683 casos. Rev Bras Med Trab. [S.I], v 9, n 1, p 33-38, 2011.

MAIDA, C.M.; APREA, L.; CALAMUSA, G.; CAMPISI, F.; FAVARO, D.; FIORINO, G.R.; FODALE, A.M.; MANIGLIA, M.L.; MARCHESE, V.; VELARDO, M.M.; Torregrossa M.V. Blood and body fluids exposure of healthcare workers in a university hospital of Palermo, Italy: a fourteen years long surveillance. Annali di Igiene, [S.I], Volume 32, n6, 2020.

MATOS, D. V. D. et al. Caracterização epidemiológica dos indivíduos que sofreram acidentes de trabalho nas macrorregiões brasileiras, nos anos de 2016 a 2018. Revista Científica Multidisciplinar Núcleo do Conhecimento, v. 1, 2019. Disponível em: < https://www.nucleodoconhecimento.com.br/saude/acidentes-detrabalho $>$.

MOREIRA, E. C. D. M. et al. Impactos diretos e indiretos na neurocognição humana, decorrentes da intoxicação por metilmercúrio e seus agravos para a saúde coletiva.

RC: 77957

Disponível em: https://www.nucleodoconhecimento.com.br/saude/exposicao-amateriais 
Research, Society and Development, v. 912, p. e4409128005, 2020. Disponível em: < https://rsdjournal.org/index.php/rsd/article/view/8005 >.

NEIVA, C. A. C. et al. Caracterização epidemiológica das intoxicações exógenas por substâncias nocivas e acidentes por animais peçonhentos em crianças no Estado do Amapá. Revista Científica Multidisciplinar Núcleo do Conhecimento, v. 1, p. 4166 , 2019.

Disponível em:

https://www.nucleodoconhecimento.com.br/saude/caracterizacao-epidemiologica >.

OLIVEIRA, Elizarbio Carneiro de. Analise epidemiológica de acidentes de trabalho com exposição a material biológico entre profissionais de enfermagem, SANARE, Sobral, v14, n1, p27-32, 2015.

REIS, L.A.; GÓMEZ LA-ROTTA, E.I.; DINIZ, P.B.; AOKI, F.H.; JORGE, J. Occupational Exposure to Potentially Infectious Biological Material Among Physicians, Dentists, and Nurses at a University. Safety and Health at Work, v 10, n4, p 445-451. 2019.

REIS, Phillipe Geraldo Teixeira de Abreu et al. Perfil epidemiológico de acidentes com material biológico entre estudantes de medicina em um pronto-socorro cirúrgico. Revista do Colégio Brasileiro de Cirurgiões. Rio de Janeiro: v. 40, n. 4, p.287292, ago. 2013.

RUAS, Edna et al. Acidentes ocupacionais com materiais perfurocortantes em hospitais de Montes Claros-MG. Revista Mineira de Enfermagem, [S.I], v16, n3 p437-443, jul./set., 2012.

SANTOS Junior EP, et al. Acidentes de trabalho com material perfurocortante envolvendo profissionais e estudantes da área da saúde em hospital de referência. Rev. Bras. Med. Trab. [S.I], v 13, n 2, p 69-75, 2015

RC: 77957

Disponível em: https://www.nucleodoconhecimento.com.br/saude/exposicao-a- 
SILVA, L. F. et al. Casos confirmados de botulismo no brasil no decênio 2010 a 2019: Uma análise das notificações. In: GALVÃO, P. V. M. (Ed.). Saúde Pública no século XXI: Uma abordagem sobre a epidemiologia. Triunfo PE: Omnis Scientia, v.1, 2020. cap. 8 , p.72-84.

TALAAT, M. Occupational exposure to needlestick injuries and hepatitis B vaccination coverage among health care workers in Egypt. American Journal of Infection Control, v 31, n 8, p 469-474, 2003.

TAPIAS, L.F.; TAPIAS L.; TORRES, S.A. Accidentes biológicos en estudiantes de Medicina. Revista de la Universidad Industrial de Santander, [S.I], v 39, n 3, p 183-189, 2007.

VASCONCELOS, A. C. et al. Acidentes com materiais biológicos envolvendo estudantes da área da saúde no período de 2008-2018. In: SILVA, B. R. D. (Ed.). Difusão do conhecimento através das diferentes áreas da medicina 5. Ponta Grossa PR: Atena Editora, v.5, 2020. cap. 5, p.38-59.

Enviado: Março, 2021.

Aprovado: Março, 2021.

RC: 77957

Disponível em: https://www.nucleodoconhecimento.com.br/saude/exposicao-a- 